\title{
AVALIAÇÃO NA EDUCAÇÃO FÍSICA ESCOLAR: SINGULARIDADES E DIFERENCIAÇÕES DE UM COMPONENTE CURRICULAR'
}

\author{
DR. WAGNER DOS SANTOS \\ Programa de Pós-Graduação em Educação Física, Centro de \\ Educação Física e Desportos, Universidade Federal do \\ Espírito Santo (Vitória - Espírito Santo - Brasil) \\ E-mail: wagner@proteoria.org
GRAD. FRANCINE DE LIMA MAXIMIANO Programa de Pós-Graduação em Educação Física, Centro de Educação Física e Desportos, Universidade Federal do Espírito Santo (Vitória - Espírito Santo - Brasil)
E-mail: francine-90@hotmail.com

\begin{abstract}
RESUMO
Este estudo tem por objetivo apresentar um diálogo com três professoras de Educação Física das séries iniciais do ensino fundamental, dedicando especial atenção para as práticas avaliativas. Define como instrumento de pesquisa a entrevista semiestruturada e como base interpretativa a análise de conteúdo. Os dados apresentam possibilidades de avaliar nas aulas de Educação Física a partir de diferentes instrumentos de registro, levando em consideração a especificidade desse componente curricular. Aponta caminhos para se projetar a avaliação, ultrapassando os discursos acadêmicos que fundamentam suas análises em diagnósticos de denúncias.
\end{abstract}

PALAVRAS-CHAVE: Educação física; ensino fundamental; avaliação educacional; narrativas.

I. O presente trabalho contou com financiamento do Cnpq (modalidade bolsa de iniciação científica). 
A avaliação educacional, sob diversos enfoques, tem sido objeto de intensos debates no Brasil desde a década de 1930. Nos últimos anos, a reflexão sobre essa temática intensificou-se, assumindo concepções epistemológicas diversas, bem como objetos de estudo. No que tange especificamente à Educação Física, é possível afirmar que as pesquisas no campo da avaliação começam a expressar suas reflexões em meados da década de 1970, influenciadas pelos trabalhos de Bloom, Pophan, Scriven, Stake, Stufflebeam e Tyler. ${ }^{2}$

Contudo, trabalhos do tipo estado da arte, como os de Santos (2002), Alves e Soares Junior (2007) e, recentemente, Macedo (201 I), têm demonstrado um reduzido número de pesquisas sobre avaliação na Educação Física. Santos (2002) e Macedo (20 I I), ao tomarem como fonte os periódicos e congressos científicos da área no período de 1930 a 2010,3 evidenciam a existência de quarenta artigos que tratam dessa temática, sendo que desses apenas sete mergulham no cotidiano escolar. ${ }^{4}$

Embora os autores, no campo da Educação em geral, como Hoffmann (200 I), Perrenoud ( 1 999) e, especificamente na Educação Física, Resende (1995) e Souza Júnior (2004), sinalizarem avanços teóricos nos discursos acadêmicos sobre avaliação educacional, os trabalhos acabavam por denunciar as mazelas das práticas pedagógicas cotidianas. ${ }^{5}$

É oportuno salientar que esse não é um problema específico dos estudos no campo da avaliação educacional, nem, tampouco, um problema específico da Educação Física. Percebermos que é preciso, conforme destacou Alves e Oliveira (2002), evidenciar mais do que a tendência de descrever a escola em seus aspectos negativos dizendo o que não há nelas ou o que não corresponde ao modelo de análise adotado. Faz-se necessário apresentar possibilidades de intervenção na/para a Educação Física que vão além da continuidade/insistência em gerar diagnósticos de denúncia.

A questão posta por essa opção se projeta no sentido de perceber o que de fato a escola faz, porque faz e com quem faz. Buscamos, com isso, compreender

2. Em pesquisa anterior demonstramos a influência desses autores na produção teórica da Educação Física (SANTOS, 2002).

3. As fontes utilizadas foram: "Catálogo de periódicos de Educação Física e esporte: 1930-2000" (FERREIRA NETO et al., 2002); revistas da área disponíveis on-line; ANPED, no período de 2001 a 2010 e; CONBRACE, 200 I, 2003, 2005 e 2007.

4. Em trabalho realizado na Educação, Barreto e Pinto (200 I) chegaram a resultados similares. De 217 artigos, 37 correspondiam a estudos empíricos, o que equivale ao menor percentual entre os trabalhos analisados.

5. As pesquisas no campo da Educação Física, têm indicado, em sua grande maioria, que os professores realizam suas avaliações com base na aptidão física, assiduidade e participação, cujo instrumento é a observação. A avaliação é realizada apenas para cumprir normas impostas por lei, ocorrendo sem planejamento e, consequentemente, sem objetivos educacionais pré-definidos (SANTOS, 2005, 2008). 
não apenas as ações prescritivas como produtoras de conhecimento escolar, mas, sobretudo, os saberes da prática, criados e recriados diariamente nos espaços e tempos escolares, pelos praticantes que os constituem.

Diante disso, nos aproximamos de uma perspectiva de pesquisar com, e não apenas sobre o professor e a escola. Buscamos contrariar esta última perspectiva por meio da indicação da produção de dados, de diálogos compartilhados e de um retorno àqueles que fazem a escola e possibilitam o desenvolvimento da pesquisa acadêmica, assumindo a escola como espaço de produção de conhecimento e os agentes sociais como praticantes ${ }^{6}$ dessas produções. Temos como objetivo, neste trabalho, ao dar visibilidade às práticas avaliativas produzidas por três professoras de Educação Física das séries iniciais do ensino fundamental, indicar caminhos e possibilidades concretas para atuação profissional.

O estudo está estruturado em duas partes. Na primeira apresentamos o referencial teórico-metodológico adotado, dedicando-nos à identificação das professoras, tipos de instrumentos e análise de dados. Posteriormente, apresentamos as práticas avaliativas das professoras, dialogando com os estudos no campo da avaliação, tanto da Educação como da Educação Física.

\section{REFERENCIAL TEÓRICO-METODOLÓGICO}

Ao realizarmos uma pesquisa com o cotidiano, buscamos compreender os saberes da prática, criados e recriados diariamente nos espaços e tempos escolares. A incorporação dessa postura nos possibilita entender a vida cotidiana como lugar antropológico onde/quando se vive as práticas de experimentação que taticamente abrem novos possíveis e/ou outras formas e forças que se enredam nos cotidianos escolares, ${ }^{7}$ favorecendo processos inventivos e de resistência (FERRAÇO, CARVALHO, 2008). Essa proposição epistemológica valoriza, conforme destaca Cinelli e Garcia (2008), as práticas dos que fazem e pesquisam a cultura produzida no contexto escolar.

Aproximamo-nos do cotidiano escolar, em especial das práticas avaliativas de professoras de Educação Física, observando-as como lugar de construção, de inventividade, de criação de alternativas e de possibilidades individuais e coletivas. Interessava-nos o modo como os professores vão (res)significando suas ações, de modo a consumir e produzir diferentes possibilidades avaliativas.

O consumo, conforme conceito de Certeau (1994), deixa de ser entendido como um elemento de transposição e apropriação mecânica, que denota passividade

6. Conceito utilizado por Certeau (1994) para decifrar os lugares de autoria daqueles que produzem os cotidianos.

7. Usamos os conceitos de lugar e tática com base nos estudos de Certeau (1994). 
por parte de quem consome, para ser substituído pelo conceito de usos, contexto de reelaboração e reapropriação no qual o usuário reconhece e produz as ações.

Assim, as artes de fazer, estilos de ação dos praticantes cotidianos, obedecem a outras regras que não aquelas da produção e do consumo oficiais, criam um jogo mediante a estratificação de funcionamento diferente e interferente, dando origem a novas maneiras de utilizar a ordem imposta (CERTEAU, 1994). No consumo os professores desenvolvem ações, fabricam formas alternativas de uso, tornando-se produtores, disseminando alternativas, manipulando, ao seu modo, os produtos e as regras.

$\mathrm{Na}$ valorização da relação de parceria, o texto apresenta os movimentos de partilhas, negociações e tessituras das redes (FERRAÇO, 2008) produzidas nos diálogos/narrativas com três professoras de Educação Física das séries iniciais do ensino fundamental, sendo duas lotadas na Prefeitura Municipal de Vitória e uma na Prefeitura Municipal da Serra. A escolha das colaboradoras da pesquisa foi realizada mediante a indicação/reconhecimento de outros profissionais da área.

As professoras Letícia, Nathália e Érica ${ }^{8}$ são formadas na Universidade Federal do Espírito Santo e possuem pós-graduação lato-sensu em cursos voltados para a área da Educação. Elas possuem experiência profissional fora do ambiente escolar com atividades físico-esportivas. Letícia e Nathália concluíram sua formação inicial em meados da década de 2000, período também em que iniciaram suas carreiras profissionais no contexto escolar. Já Érica concluiu sua formação inicial em 1992, tendo 19 anos de experiência na área da Educação Física escolar.

É preciso ressaltar que trabalhar com narrativas representa uma possibilidade de fazer valer as dimensões de reconhecimento dos atores da vida cotidiana, como protagonistas de seu processo de formação, configurando-se como vozes autorizadas e com legitimidade para falar de suas práticas, pois, como salienta Alves et al (2007, p. 26):

Entre as questões teórico-metodológicas, as narrativas, originadas das conversas, depoimentos ou escritos pessoais, formando um tipo especial de texto, vêm permitindo desenvolver tanto as metodologias próprias da história oral e da história de vida, como uma história de biografias de pessoas comuns, acumulando dados de caráter antropológico, etnográfico e sociológico [...].

\section{AVALIAÇÃO NA EDUCAÇÃO FÍSICA ESCOLAR: UM DIÁLOGO COM AS PROFESSORAS}

Como base nas questões do roteiro de entrevista, bem como nas narrativas das professoras, foi possível construir os seguintes eixos temáticos de análise: papel

8. Com objetivo de garantir o anonimato das docentes colaboradoras da pesquisa, atribuímos-lhe pseudônimos. 
da avaliação na Educação Física; para que avaliar; quem, quando e onde avaliar; instrumentos avaliativos; por que avaliar.

Ao abordar o papel da avaliação na Educação Física nas séries iniciais do ensino fundamental, Nathália destaca a possibilidade de oferecer elementos para se adequar os objetivos de ensino ao aprendizado dos alunos. Em seu dizer:

Acredito que para nós, da Educação Física, a avaliação, vem como um complemento do seu trabalho, até onde você está conseguindo alcançar seu objetivo. Eu acho que para nós, dentro da Educação Física, ajuda perceber o quanto o aluno progrediu.

Na narrativa da professora Érica, identificamos um discurso centrado em sua prática, em que destaca a relação avaliação/objetivos de ensino e avaliação/ aprendizado. A avaliação escolar, nesse caso, não se resume em atribuir nota ou classificar o aluno, nem tampouco se centraliza no aprendizado, ela fornece pistas para que os envolvidos possam orientar suas ações a favor da formação. Assim, o par dialético, ensino e aprendizagem, orientam a prática avaliativa em um movimento que reconhece a necessidade de se investigar tanto a ação pedagógica das professoras como os processos de aprendizado dos alunos.

A professora Letícia ressalta a relação entre avaliar e pesquisar. Para ela:

Você avalia a todo o momento! Para mim, avaliar é pesquisar a ação de dar aula, de intervir. Você esta pesquisando o tempo todo, o teu aluno, as suas ações, o seu meio e tudo que acontece, e tudo isso é fundamental para entrar na avaliação.

O processo pedagógico demanda da prática de pesquisa e a avaliação é um momento essencial para sua materialização. Essa afirmação se aproxima da perspectiva avaliativa defendida por Santos $(2005,2008)$, por projetá-la como parte do processo de tessitura de conhecimento fundamentada no prospectivo, na diferença, que se produz sem modelos fechados, focalizada nos saberes e nos ainda não saberes em desenvolvimento. A avaliação sobre esses preceitos se constitui como

[...] um processo significativo para a reflexão sobre a prática social, a prática escolar e a interação entre estes âmbitos. Sua capacidade reconstrutiva do processo contribui para a reflexão sobre a ação pedagógica, possibilitando o desenvolvimento de um processo de avaliação da própria prática docente. A avaliação como ato de reconstrução se constitui em processo formativo para as professoras, articulando dialeticamente reflexão e ação; teoria e prática; contexto escolar e contexto social; ensino e aprendizagem; processo e produto; singularidade e multiplicidade; saber e não-saber; dilemas e perspectivas (ESTEBAN, 2002, p. 12).

A pretensão quantitativa cede espaço para a intenção indiciária, em que os praticantes envolvidos têm como objetivo produzir/registrar/interpretar as informações em um exercício constante de leitura de sinais, de indícios, a partir dos quais 
se manifestam juízos de valores e tomadas de decisões (SANTOS, 2008). Entretanto, fica-nos a pergunta: como dar sentido à avaliação levando em consideração a especificidade da Educação Física quando comparada aos demais componentes curriculares? A narrativa de Letícia nos fornece a dimensão dessa complexidade, ao destacar a dificuldade em realizar a avaliação no início da carreira docente.

\begin{abstract}
Uma grande dificuldade que eu tinha era de materializar a avaliação. Como transformar todas as informações, que vêm ali em toda a minha aula, em avaliação, nota! Essa sempre foi uma grande dificuldade minha. Mas, o que será que é avaliar? Essa era a pergunta no início da carreira: eu tenho que dar prova escrita na Educação Física? Eu tenho que dar trabalho? Por que só isso que é avaliar? Ou em outro caso: avaliar é só eu observar se aluno participa ou não participa?
\end{abstract}

As dificuldades apresentadas por Letícia, no início da carreira profissional, juntamente com as possibilidades que ela criava/consumia para sua prática avaliativa, remetem-nos a uma discussão mais ampla, pois essa não é uma questão apenas de coleta de informações, mas dos sentidos atribuídos à avaliação. Nesse caso, é preciso ressaltar o fato de estarmos tratando de um componente curricular que assume um estatuto epistêmico que privilegia outra relação com o saber, ${ }^{9}$ comparada com as demais disciplinas escolares. Para Schneider e Bueno (2005), a Educação Física não privilegia o saber-objeto que pode ser incorporado pela relação epistêmica com os objetos, mas, sim, o saber concretizado por meio do domínio de uma atividade. ${ }^{10}$

Depreendemos desse debate que a criança não aprende apenas quando lê, escreve e fala. Aprende também quando se expressa corporalmente, uma vez que se movimentar não pode ser considerado apenas natural, espontâneo, biológico; relaciona-se, principalmente, com questões culturais, afetivas e sociais. Os autores alertam que, no trabalho com a Educação Física, mais importante do que conseguir sistematizar uma explicação do que se aprendeu, certamente, é a experiência vivenciada.

Os conhecimentos com os quais a disciplina Educação Física lida, como os esportes, jogos, danças, lutas e ginástica, são atividades constantemente submetidas a minivariações

9. Para Charlot (2000, p. 78-79), "[...] a relação com o saber é relação com o tempo. A apropriação do mundo, a construção de si mesmo, a inscrição em uma rede de relações com os outros - 'o aprender' — requerem tempo e jamais acabam. [...] Esse tempo, por fim, se desenvolve em três dimensões, que se interpenetram e se supõem uma à outra: o presente, o passado, o futuro".

10. Ao discutir sobre as figuras do aprender, Charlot (2000, p. 66) indica quatro formas dessas se manifestarem: "I possui relação com objetos-saberes, objetos nos quais os saberes estão incorporados [...]; 2 - tem a ver com objetos cujo uso deve ser aprendido [...]; 3 - se projeta em atividades a serem dominadas, as quais possuem estatutos variados [...]; e, 4 - se manifesta em dispositivos relacionais, os quais só podem ser apropriados na relação com o outro". Charlot (2000, p. 7I) destaca que essas figuras podem ser resumidas em três: "[...] constituição de um universo de saberes-objetos, ação no mundo, regulação da relação com os outros e consigo". Apropriamo-nos dessas três figuras neste estudo. 
de situações de aplicação, por isso a dificuldade de expô-las integralmente em forma de enunciados. Fazer com, nesse sentido, indica o tipo de investigação que se pode desenvolver quando se busca compreender o conhecimento que os alunos e alunas conseguiram mais incorporar do que sistematizar em forma de enunciados [...] (SCHNEIDER; BUENO, 2005, p. 40, grifo do autor).

Essas reflexões trazem uma gama de indagações que perpassam pelo próprio questionamento sobre o papel da Educação Física no contexto escolar, sua singularidade e significação. A Educação Física, ao lidar com a relação do saber-domínio e saber-relacional que se centraliza na dimensão do fazer com, subverte a forma escolar. A escola é o lugar da palavra, da linguagem, ou de outras formas de simbolização do mundo, do texto, dos saberes sistematizados cujo modo de existência é a linguagem, por isso sua valorização da dimensão falar de em contraposição ao fazer com, sobretudo, nas práticas avaliativas. Se a escola é o lugar do falar de e do escrever sobre, como avaliar os processos de ensino e aprendizado em uma disciplina, Educação Física, que assume como estatuto epistemológico o fazer com?

As práticas avaliativas criadas por Letícia durante seu processo formativo como professora de Educação Física, "' evidenciam algumas possibilidades.

Eu estava vendo que não era só uma questão de jogar no papel, porque, às vezes, o meu aluno tem dificuldade de materializar o que ele aprendeu para papel. Aí eu falei: 'Eu não posso cobrar do meu aluno só isso!' Hoje eu trabalho com diversos instrumentos avaliativos. É a junção deles que me dá uma noção de nota. No primeiro ano, por exemplo, nós não temos nota, temos uma ficha avaliativa, onde fazemos relatórios descritivos, registramos o avanço do aluno e suas dificuldades. Para chegar a esse registro, eu faço várias avaliações, por exemplo: eu trabalho muito com imagem. Então, tudo que eu acho interessante, tiro foto, ou filmo. Com aluno de primeiro e segundo ano eu trabalho com desenho, eles não têm o domínio da palavra, eu trabalho também com construção de brinquedo que vai fazer parte do mosaico no final do trimestre que serve como registro avaliativo.

A forma de significar o lugar e as possibilidades de uso dos saberes compartiIhados pela/na Educação Física no contexto escolar perpassa pelo entendimento de sua singularidade/diferenciação, fato esse, de certa forma, sinalizado pela professora Letícia ao significar diferentes formas de registro para captar o saber-domínio e o saber-relacional, bem como a dificuldade manifestada em transformar o saber-domínio em saber-objeto que deveria ser enunciado pela linguagem, no caso, escrita, por parte dos alunos. Nesse ponto, compartilhamos das leituras de Charlot (2009, p. 243) quando salienta:

II. As produções acadêmicas têm indicado várias possibilidades de instrumentos avaliativos: fichários cumulativos, autoavaliação (DARIDO; RANGEL, 2005); elaboração de diários, listas de auto-checagem (LUIS, 20 I 0); gráfico de participação, trabalhos escritos, desenho e questionários (SANTOS, 2005). 
[... ] a Educação Física não é uma disciplina escolar 'como as demais'. E acrescento: felizmente. Não é igual às demais porque ela lida com uma forma do aprender que não a apropriação de saberes-enunciados. Em vez de tentar anular ou esconder essa diferença, dever-se-ia destacá-la e esclarecê-la. $\bigcirc$ fato de que é uma disciplina diferente não significa que tem menos legitimidade do que as demais disciplinas. Em vez de se esforçar para aparentar-se normal, conforme a norma dominante de legitimidade escolar, a Educação Física deveria, a meu ver, legitimar-se por referência a outra norma, a outra figura do aprender.

fato de a Educação Física privilegiar a dimensão do fazer com não exclui a possibilidade de se materializar o saber-domínio em saber-objeto, embora essa não seja sua especificidade nem tampouco seu objetivo, fato esse observado na seguinte narrativa:

Meus alunos têm ainda o caderno de Educação Física, como se fosse um diário, eu chamo de diário do aluno. Quando eles estão começando, eu direciono mais o que tem que ser colocado, mas, por exemplo: hoje a minha $4^{\mathrm{a}}$ série, eles escrevem, eu só dou visto, eles fazem o registro da semana, do que eles aprenderam na Educação Física. Eu deixo, entre aspas, 'mais livre'. No diário, eu consigo captar coisas que eles não falam para mim, isso é importante (PROFESSORA LETICIA).

Tanto o diário como o desenho possibilitam que o aluno materialize, mediante a transformação de saber-domínio e do saber-relacional em saber-objeto, as atividades que demarcaram suas experiências corporais. ${ }^{12}$ Nele, a professora solicita aos alunos para que narrem suas experiências. Questões como "o que faço com o que eu aprendi nas aulas de Educação Física? Como me senti na aula? Quais experiências me marcaram? Quais são as suas implicações para a relação consigo e com os outros?", orientam sua escrita.

O diário se apresenta como lugar de produção de conhecimento, espaço em que se registram as experiências dos alunos, transformando o saber-domínio e saber-relacional em saber-objeto.

Uma forma de se configurar a transformação do saber-domínio e saber-relacional em saber-enunciado é apresentada por Nathália:

Eu apliquei a auto-avaliação no último bimestre do ano passado e esse trimestre eu pretendo fazer também. Os alunos se dão nota com base na participação e no modo como eles se enxergam fazendo a aula. Nas primeiras turmas, é o crescimento gradual, nas turmas de $3^{\mathrm{a}}$ e $4^{\mathrm{a}}$ série, dou atividade escrita mais a participação.

12. Bondía (200 I) afirma que a informação é contrária à experiência; que informação é o que acontece, enquanto a experiência é o que nos acontece. A experiência "[...] se adquire no modo como alguém vai respondendo ao que the vai acontecendo ao longo da vida e no modo como vamos dando sentido ao acontecer do que nos acontece" (BONDIÁ, 200I, p. 27). 
O sentido da autoavaliação é fazer com que o aluno assuma protagonismo em seu processo educativo, se constituindo co-responsável da aprendizagem. ${ }^{13} \mathrm{~A}$ autoavaliação gera a necessidade de um debate com os alunos e professores sobre seu uso, uma vez que, segundo Boas (2002, p. 137) é imprescindível "[...] que os alunos sejam preparados para se avaliarem, de modo que possam compreender os objetivos principais de sua aprendizagem e o que fazer para atingi-los". Nesse movimento, se faz necessário entender que a centralização da autoavaliação nos atributos relacionados a comportamentos e atitudes, tão comuns na Educação Física, não fornece dados mais amplos para visualizarmos os processos de ensino e aprendizagem.

Waiselfisz (1998) salienta ainda a necessidade de não assumirmos a autoavaliação como um ritual de fim de curso, nem como um mecanismo externo ou à margem do conjunto das práticas desenvolvidas pelo processo que está sendo avaliado, mas "[...] uma parte solidária da totalidade representada por uma estratégia ou um estilo de gestão pedagógica que abre marcos de participação e decisão aos agentes direta ou indiretamente envolvidos no processo" (WAISELFISZ, I 998, p. 60).

Nessa perspectiva, a avaliação se caracteriza com uma ação sistemática de registro e acompanhamento, por parte de alunos e professores, de seus processos formativos, possibilitando um espaço e tempo para que participem ativamente da sua ação. Perguntar por que uns alunos aprendem e outros não, deixa de ser suficiente; há de se indagar a dinâmica que favorece a aprendizagem de cada um e os mecanismos utilizados para responder às questões postas (ESTEBAN, 2003).

Apesar da centralidade da prática avaliativa estar no aluno, ela não pode se restringir aos seus processos de aprendizado, pois como destaca Letícia

\begin{abstract}
A avaliação não é minha, eu me avalio, eu avalio o aluno e o aluno me avalia, e a escola avalia a minha aula. Então, quando eu filmo, eu registro, eu dou voz ao meu aluno, ali, no início da aula, durante e no final, eu estou sendo avaliada por eles, e eu estou avaliando eles, e essas duas avaliações formam a avaliação da aula. A partir do momento que um aluno vira e fala: 'Tia a aula esta chata', eu tenho que parar para pensar. Eu dou muito valor para o meu aluno.
\end{abstract}

As avaliações estabelecem com os alunos e os professores de Educação Física uma relação para além do diagnóstico e das propostas de mensuração, fornecendo indícios dos processos em desenvolvimento, assinalando trilhas não percebidas, que devem ser consideradas e exploradas dentro da singularidade das práticas pedagógicas

13. O uso da autoavaliação nas aulas de Educação Física não é novo, se faz presente nos primeiros estudos realizados no campo (FLEGNER, 1976; LORENZETTO, 1977). Sua elaboração conceitual perpassa pela influência teórica da psicologia comportamental (BARRETO, 1981; JOSUÁ, 1985); pelas teorias críticas (ALEGRE, 1993; RESENDE, 1995) e; pelas teorias pós-críticas (LACERDA, 200I). 
(SANTOS, 2008). As avaliações se encontram a serviço da ação em processo, alimentando e reorientando o percurso da aprendizagem do estudante, não havendo "a avaliação", mas um conjunto de avaliações que sinalizam o caminhar dos alunos, dos professores, das instituições formativas, no seu processo de aprender, ensinar e formar. Sendo assim,

[... um professor, ao avaliar o seu aluno, deve também avaliar a sua própria forma de inserção na sociedade, o seu papel, as suas condições de trabalho, a sua formação, a sua metodologia, os recursos por ele utilizados em sala de aula. A avaliação transforma-se em conhecimento da realidade, e neste sentido é fundamental que o professor se preocupe em analisar o aluno numa perspectiva ampla, exigindo para isso a utilização de atividades de ensino que permitam uma participação coletiva efetiva, através da utilização de formas variadas de expressão (DALBEN, 1998, p. 79).

Nessa configuração, avaliar é essencialmente uma prática de questionar, questionar-se, sendo necessário observar e promover experiências educativas que signifiquem provocações intelectuais relevantes na direção da formação.

\section{CONSIDERAÇÕES FINAIS}

As narrativas das professoras colaboradoras deste estudo não apenas forneceram possibilidades de avaliar as aulas de Educação Física, mas de questionarmos o próprio estatuto epistemológico de que trata essa disciplina. Sinalizam, com isso, a necessidade da Educação Física, como componente curricular, avaliar o processo ensino e aprendizagem e se avaliar, privilegiando o fazer com ao invés do falar de e escrever sobre.

Percebemos, nas maneiras e artes de fazer das professoras de Educação Física, o uso da avaliação como prática de pesquisa, consubstanciados pela criação/consumo de diferentes instrumentos de registro, dentre os quais se destacam: relatório descritivo, desenhos, fotos, filmes, diários e autoavaliação. De maneira colaborativa e co-participativa, esses instrumentos favorecem o processo de reflexão sobre e para a ação, permitindo uma análise da realidade, bem como a projeção de novas ações centradas no ensino e na aprendizagem. Fornecem indícios do modo como os praticantes se apropriam dos saberes escolares.

As análises projetadas neste estudo reforçam a necessidade de novas pesquisas com o intuito de dar visibilidade às práticas avaliativas de professores, uma vez que elas podem projetar a contribuição da Educação Física na escola, o que se ensina e se aprende, o que se aprende com o que se ensina, bem como os objetivos que constituem as práticas pedagógicas dos professores e as apropriações realizadas pelos alunos na relação com o saber. 


\section{Evaluation in Physical Education: Singularities and Differentiation of a Curriculum Component}

ABSTRACT: This study aims to present the dialogue with three teachers of Physical Education from the earlier grades of elementary school, giving a special attention to the evaluation practices. It was conducted a semi-structured interview as the research tool, and the analysis of the content was used for the interpretative basis. Results show possibilities of evaluating Physical Education classes based on different recording instruments, considering the specificity of this curriculum component. It shows directions to enhance the evaluation, in order to overcome academic discourses which support their analysis in diagnosis of complaints.

KEYWORDS: Physical Education; Elementary School; Educational Evaluation; Narrative.

\section{Evaluación en la Educación Física escolar: singularidades y diferencias de un componente curricular}

RESUMEN: Este estudio tiene por objetivo presentar un diálogo con tres profesoras de Educación Física de las series iniciales de la enseñanza fundamental, dedicando especial atención a las prácticas evaluativas. Define como instrumento de pesquisa la entrevista semiestructurada y como base interpretativa el análisis de contenido. Los datos presentan posibilidades de evaluar las clases de Educación Física a partir de diferentes instrumentos de registro, llevando en consideración la especialidad de ese componente curricular. Indica caminos para se proyectar la evaluación ultrapasando los discursos académicos que fundamentan sus análisis en diagnósticos de denuncias.

PALABRAS CLAVE: Educación Física; enseñanza fundamental; evaluación educacional; narrativa.

\section{REFERÊNCIAS}

ALEGRE, A. N. A avaliação em Educação Física: ação docente nas escolas oficiais de primeiro grau. 1993. I 52 f. Dissertação (Mestrado em Educação Física) - Escola de Educação Física, Universidade de São Paulo, São Paulo, 1993.

ALVES, N. et al. Nós e nossas histórias em imagens e sons - uma história em imagens. In: AMORIM, A. C. R. de (Org.). Passagens entre o moderno para o pós-moderno: ênfase e aspectos metodológicos das pesquisas sobre currículo. Campinas: UNICAMP, GT Currículo da ANPEd, 2007. p. $21-28$.

ALVES, N.; OLIVEIRA, I. B. Uma história da contribuição dos estudos do cotidiano escolar ao campo do currículo. In: LOPES, A. C.; MACEDO, E. (Org.). Currículo: debates contemporâneos. São Paulo: Cortez, 2002. p. 78-102.

ALVES, W. F; SOARES JUNIOR, N. E. Educação física escolar e a avaliação: análise dos trabalhos apresentados no GTT-Escola no período de 1997 a 2005. In: CONGRESSO BRASILEIRO DE CIÊNCIAS DO ESPORTE, I5., 2007. Anais... Recife: CBCE, 2007. 
BARRETO, E. S. S.; PINTO, R. P. Avaliação na educação básica (1990- 1998). Brasília: MEC: Inep: Comped, 200I.

BARRETO, R. P. Educação Física: avaliação no ensino. Revista Brasileira de Educação Física e Desportos, Brasília, ano 10, n. 47, p. 59-61, jul./set. 1981.

BOAS, B. F. V. Construindo a avaliação formativa em uma escola de educação infantil e fundamental. In: . (Org.). Avaliação: políticas e práticas. Campinas: Papirus, 2002. p. I| 3- 443.

BONDÍA, J. L. Notas sobre, a experiência e o saber da experiência. Revista Brasileira de Educação, Campinas, n. 19, p. 20-28, jan./abr. 2001.

CERTEAU, M. de. A invenção do cotidiano: artes de fazer. 8. ed. Petrópolis: Vozes, 1994.

CHARLOT, B. Da relação com o saber: elementos para uma teoria. Porto Alegre: Artes Médicas Sul, 2000.

. Ensinar a Educação Física ou ajudar o aluno a aprender o seu corpo-sujeito? In: DANTAS JUNIOR, H. S.; KUHN, R.; RIBEIRO, S. D. D. Educação Física, esporte e sociedade: temas emergentes. São Critóvão: Ed. da UFS, 2009. v. 3, p. 23 I-246.

CINELLI, M. L.; GARCIA, A. Olhar sem ver: escolas invisíveis e currículos praticados. In: REUNIÃO ANUAL DA ASSOCIAÇÃO NACIONAL DE PÓS-GRADUAÇÃO E PESQUISA EM EDUCAÇÃO, 31 ., 2008, Caxambu. Anais... Caxambu: ANPEd, 2008.

DALBEN, A. A avaliação escolar: um processo de reflexão da prática docente e da formação do professor no trabalho. 1998. 266 f. Tese (Doutorado em Educação) - Faculdade de Educação, Universidade Federal de Minas Gerais, Belo Horizonte, 1998.

DARIDO, S. C.; RANGEL, I. C. A. Educação Física na escola: implicações para a prática pedagógica. Rio de Janeiro: Guanabara Koogan, 2005.

ESTEBAN, M. T. A avaliação no cotidiano escolar. In: (Org.). Avaliação: uma prática em busca de novos sentidos. 4. ed. Rio de Janeiro: DP\&A, 2002. p. 7-28.

. Pedagogia de projetos: entrelaçando o ensinar, o aprender e o avaliar à democratização do cotidiano escolar. In: SILVA, J. F.; HOFFMANN, J.; ESTEBAN, M. T. (Org.). Práticas avaliativas e aprendizagens significativas: em diferentes áreas do currículo. Porto Alegre: Mediação, 2003. p. 81-92.

FERRAÇO, C. E. A pesquisa em educação no/do/com o cotidiano escolar. In: ..; PEREZ, C. L. V.; OLIVEIRA, I. B. Aprendizagens cotidianas com a pesquisa: novas reflexões em pesquisa nos/dos/com os cotidianos das escolas. Petrópolis: DP et Alii, 2008. p. 23-34.

FERRAÇO, C. E.; CARVALHO, J. M. Currículos realizados e/ou vividos nos cotidianos de escolas públicas: sobre como concebemos a teoria e a prática em nossas pesquisas In: MACEDO, E.; MACEDO, R. S.; AMORIM, A. C. (Org.). Como nossas pesquisas concebem a prática e com ela dialogam? Campinas: FE/UNICAMP, 2008. p. 4-I3. 
FERREIRA NETO, A. et al. Catálogo de periódicos de Educação Física e esporte (1930-2000). Vitória: Proteoria, 2002.

FLEGNER, A. J. Critérios de avaliação escolar em Educação Eísica de I I anos em diante. Revista Brasileira de Educação Física e Desportos, Brasília, ano 8, n. 30, p. 66-80, abr.jun. 1976.

HOFFMANN, J. Avaliar para promover: as setas do caminho. Porto Alegre: Mediação, 200 I. JOSUÁ, P. Considerações sobre avaliação em Educação Física curricular. ARTUS: Revista de Educação Física e Desportos, Rio de Janeiro, ano 8, n. 15, p. 22-24, 1985.

LACERDA, L. L. Fundamentos para a auto-avaliação como "experiência de si" na prática pedagógica da Educação Física escolar. 200 I . 214 f. Dissertação (Mestre em Educação Física) - Universidade Gama Filho, Rio de Janeiro, 2001.

LORENZETTO, L. A. Auto-avaliação em alunos de $8^{a}$ série: introdução. Revista Esporte e Educação, São Paulo, ano 7, n. 44, p. 28-34, set./out. 1977.

LUIS, S. M. B. De que avaliação precisamos em arte e Educação Física? In: SILVA, J. F; HOFFMANN, J.; STEBAN, M. T. (Org.). Práticas avaliativas e aprendizagens significativas em diferentes áreas do currículo. 9. ed. Porto Alegre: Mediação, 2009. p. 34-44

MACEDO, L. R. Avaliação na Educação Física escolar nas séries iniciais do ensino fundamental: práticas e saberes. Vitória, 20II. Relatório parcial do Programa de Iniciação Científica da Universidade Federal do Espírito Santo.

PERRENOUD, P. Avaliação: da excelência à regulação das aprendizagens: entre duas lógicas. Porto Alegre: Artes Médicas, 1999.

RESENDE, H. G. Princípios gerais da ação didático-pedagógica para avaliação do ensino-aprendizagem em Educação Física escolar. Motus Corporis, Rio de Janeiro, ano 2, n. 4, p. 4- I5, 1995.

SANTOS, W. Avaliação na Educação Física escolar: análise de periódicos do século XX. 2002. 138 f. Monografia (Licenciatura em Educação Física) - Centro de Educação Física e Desportos, Universidade Federal do Espírito Santo, Vitória, 2002.

- Currículo e avaliação na Educação Física: do mergulho à intervenção. Vitória: Proteoria, 2005.

SANTOS, W. Currículo e avaliação na Educação Física: práticas e saberes. In: SCHNEIDER, O. et al. (Org.). Educação Física esporte e sociedade: temas emergentes. São Cristovão: Ed. da UFS, 2008. v. 2, p. 87-106.

SCHNEIDER, O.; BUENO, J. G. A relação dos alunos com o saber compartilhado nas aulas de Educação Física. Movimento: revista da Escola de Educação Física, Porto Alegre, v. I I, n. I, p. 23-46, jan./abr. 2005. 
SOUZA JÚNIOR, M. Práticas avaliativas e aprendizagens significativas em Educação Física: trajetória, orientações legais e implicações pedagógicas. Pro-Posições, Campinas, v. I 5, n. 2, maio/ago. 2004.

WAISELFISZ, J. Avaliação participativa. Idéias, São Paulo, n. 8, p. 59-66, 1998.

Recebido em: 23 mar. 2012

Aprovado em: 22 maio 2013

Endereço para correspondência:

Wagner dos Santos

Caixa Postal 9905

AGF UNIVERSITÁRIA

Rua Arthur Czartoryski 455 Loja I

CEP.: 29060-974 